\title{
Correlação entre a Resistência à Corrosão e as Tensões Residuais de um Aço Inoxidável Lean Duplex UNS S32304 Tratado Termicamente.
}

Merlo, P. P. ${ }^{1}$; Milagre, M. X. ${ }^{1}$; Machado, C.S.C. ${ }^{1}$; Macêdo M. C. S. ${ }^{1}$; Orlando, M. T. D. ${ }^{1}$

1 Programa de Pós-Graduação em Engenharia Mecânica, Universidade Federal do Espírito Santo, Vitória, ES, Brasil

\begin{abstract}
O aço inoxidável lean duplex UNS S32304, objeto de estudo deste trabalho, apresenta um custo inferior em relação a outros AID devido à substituição parcial do níquel por nitrogênio como elemento estabilizador de austenita. Tratamentos térmicos podem promover a precipitação de fases secundárias nos AID, resultando no empobrecimento em cromo nas regiões adjacentes aos precipitados. Tal fenômeno é conhecido como sensitização e é prejudicial à resistência à corrosão localizada do material. Neste trabalho, amostras do aço UNS S32304 foram tratadas termicamente por 8 horas na temperatura de $475^{\circ} \mathrm{C}$ e resfriadas sob duas condições, ao ar e na água do mar. Para avaliar a resistência à corrosão foram realizados ensaios DL-EPR nas amostras como recebida pelo fabricante e tratadas, e os resultados foram correlacionados com os dados de tensão residual em cada amostra, obtidas por difração de raios $\mathrm{x}$. Foi medida a microdureza Vickers com auxilio de microdurômetro.
\end{abstract}

Palavras chaves: aços inoxidáveis duplex, resistência à corrosão, tensão residual.

\section{Introdução}

Os aços inoxidáveis duplex (AID) apresentam microestrutura constituída por um balanço entre as fases ferrita (CCC) e austenita (CFC) em frações volumétricas aproximadamente iguais. A austenita confere elevada resistência mecânica e à corrosão sob tensão, enquanto a ferrita contribui com uma boa ductilidade e resistência à corrosão em geral. Esse material é amplamente empregado na indústria petroquímica, de papel e celulose e na construção civil [1].

Em sua fabricação, após o processo termo-mecânico de laminação e tratamento térmico de solubilização para obtenção da estrutura bifásica, tensões residuais podem ser impostas no material, as quais tendem prejudicar as propriedades mecânicas [2].
O emprego de tratamentos térmicos pode também promover a precipitação de fases secundárias nos AID, resultando no empobrecimento em cromo nas regiões adjacentes aos precipitados. Tal fenômeno é conhecido como sensitização e é prejudicial à resistência à corrosão localizada do material [3].

O estudo de como as variações de tensões residuais se correlacionam com as propriedades corrosivas dos metais torna-se importante para que falhas prematuras sejam evitadas [4]

\section{Materiais e Métodos}

Foram utilizadas tiras de aço inoxidável duplex UNS S32304, fabricadas por processo de laminação a quente seguido de tratamento térmico de solubilização a $1038^{\circ} \mathrm{C}$. As tiras foram cortadas em máquina de corte automática e apresentaram as dimensões finais de $72 \times 72 \times 1,8 \mathrm{~mm}$ 
As amostras foram tratadas termicamente em forno tipo mufla programável, a $475^{\circ} \mathrm{C}$ sob uma atmosfera ambiente com tempo de 8 horas e resfriadas ao ar e água do mar (maior severidade). As amostras foram classificadas conforme a Tabela 1.

Tabela 1: Características das amostras

\begin{tabular}{|l|l|}
\hline Amostras & Características \\
\hline CR & Como recebida pelo fabricante \\
\hline 475 AR & Resfriada ao ar \\
\hline 475 ÁGUA & Resfriada à água do mar \\
\hline
\end{tabular}

A superfície das amostras foi preparada com desbaste eletroquímico, conforme a norma ASTM-E1558 [4], para remoção da camada de óxidos formada. Utilizouse solução de $\mathrm{H}_{2} \mathrm{SO}_{4} 25 \%$ por 10 minutos para a amostra do grupo CR e 20 minutos para as amostras do grupo 475. Para as medidas de tensão residual foi utilizado um difratômetro de raios- $x$, da marca Rigaku, numa geometria Bragg-Brentano e radiação $\operatorname{CuK}_{\alpha}(\lambda=$ 1,5419 ). Foi acompanhado o comportamento do pico 420 da fase austenítica, conforme a norma SAE HS784. A amostra foi fixada na posição $\phi=0^{\circ}$ que representa a direção paralela a direção de laminação. As tensões residuais foram calculadas pelo método do $\operatorname{sen}^{2} \psi$. Para a determinação da posição $2 \theta$ do pico analisado utilizou-se o método de localização em função da intensidade por meio da função matemática Pearson7A com o auxilio do programa gráfico FityK. Para esta análise, o módulo de elasticidade e coeficiente de Poisson utilizados foram E = $190 \mathrm{GPa}$ e $\mathrm{v}=0,305$, respectivamente[2,5].

O ensaio de microdureza foi realizado utilizando-se um microdurômetro (Pantec modelo HDX-1000TM) e o penetrador tipo Vickers, com carga de 10 kgf e duração de aplicação de 15s. Foram realizadas 15 indentações de maneira aleatória em cada fase da amostra, utilizando a face superior das amostras para realização das medidas, já que nessa região os grãos encontramse maiores, facilitando a medida nas distintas fases. Os ataques químicos utilizados para revelar as fases foram: ataque eletrolítico $10 \mathrm{~N}$ de $\mathrm{KOH}, 2,5 \mathrm{~V}$ por $5 \mathrm{~s}$ e ataque eletrolítico com solução de ácido oxálico 10\%, a $6 \mathrm{~V}$ durante 20s [6].
As amostras foram embutidas em resina polimérica ligadas a um fio de cobre para fechar circuito com o potenciostato da marca Autolab Type III e lixadas até \#600. Os ensaios de corrosão foram repetidos pelo menos três vezes em cada amostra e iniciados após o potencial de circuito aberto ter atingido um estado estacionário próximo ao tempo de $30 \mathrm{~min}$. Após estabilização do potencial, foi iniciada a varredura na direção anódica a uma taxa de $1 \mathrm{mV}_{\text {SCE.S-1 }}{ }^{-}$até um potencial de 0,3 $V_{S C E}$ e então a varredura foi invertida na direção catódica, mantendo-se a mesma taxa de varredura, até o potencial de circuito aberto. A solução consistiu de $2 \mathrm{M}$ de $\mathrm{H}_{2} \mathrm{SO}_{4}+0,01 \mathrm{M}$ de KSCN. O grau de sensitização do material foi avaliado a partir da razão $\mathrm{Ir} / \mathrm{la}$ onde la é a máxima corrente atingida na varredura anódica e $I_{r}$ é a máxima corrente atingida na varredura no sentido catódico [7].

\section{Resultados e Discussão}

\subsection{Tensão Residual}

Gráficos deformação $\left(\varepsilon_{\phi \psi}\right)$ em função do $\operatorname{sen}^{2} \Psi$ foram construídos a partir dos difratogramas e os valores de tensão residual para cada condição analisada puderam ser calculados, como ilustrado na Figura 1. A partir destes resultados foi elaborado o gráfico da Figura 2, que representa as tensões residuais médias nas três amostras. O processo de laminação realizado em uma determinada direção com baixa penetração gera tensões residuais compressivas na superfície e trativas no interior do metal [5]. Após os tratamentos térmicos pode-se observar um relaxamento de tensões na fase austenítica, sendo esse efeito mais pronunciado para a amostra resfriada ao ar. Tal fato pode estar relacionado com a difusão dos elementos de liga, movimentação de defeitos, aumento do tamanho de grão e oxidação do material, os quais apresentaram um maior tempo para ocorrência na amostra 475 AR [8]. No que diz respeito à fase ferrítica, as tensões residuais compressivas foram aumentadas. Em tratamentos à temperatura de $475^{\circ} \mathrm{C}$ há previsão de precipitação da fase alfa linha $\left(\alpha^{\prime}\right)$ na matriz ferrítica, o que promoveria a introdução de tensões residuais compressivas, além daquelas geradas devido à expansão da austenita. 


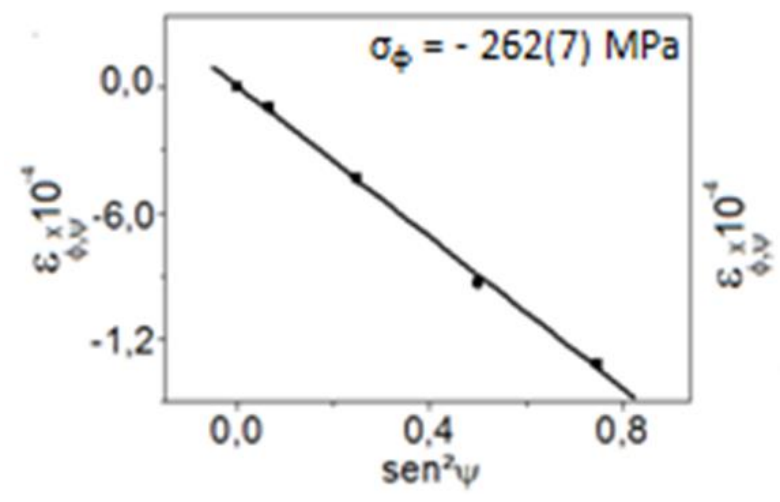

Figura 1: Deformação do pico 420 da fase austenita em função do $\operatorname{sen}^{2} \Psi$ para a amostra CR.

Tensões Residuais (MPa)

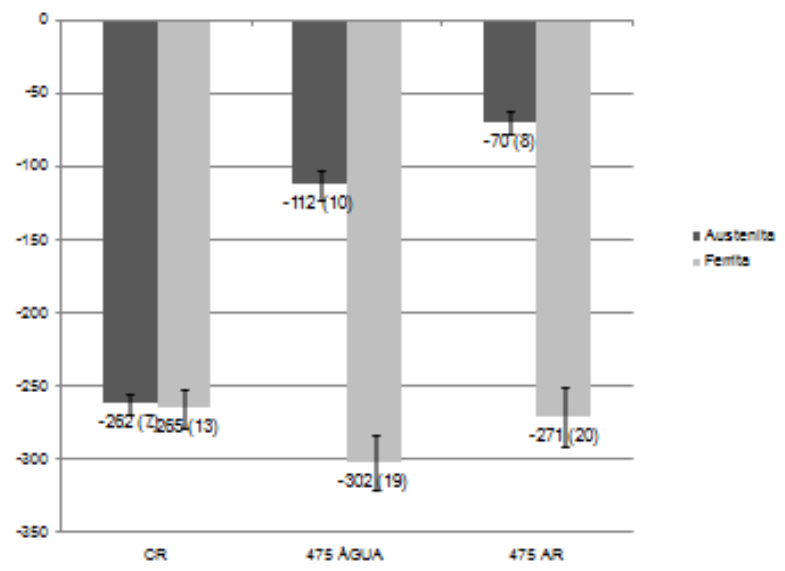

Figura 2: Tensões residuais médias calculadas para as três amostras.

\subsection{Microdureza Vickers}

Pela análise da Figura 3 concluí-se que após o tratamento térmico há um aumento na microdureza das amostras. Isso pode ser explicado também pela formação de $\alpha^{\prime}$. A diferença entre os parâmetros de rede entre $\alpha^{\prime}$ e ferrita introduz tensões internas que prejudicam a mobilidade de discordâncias, o que resultaria em aumento da dureza da liga [10].

Microdureza Vickers (HV)

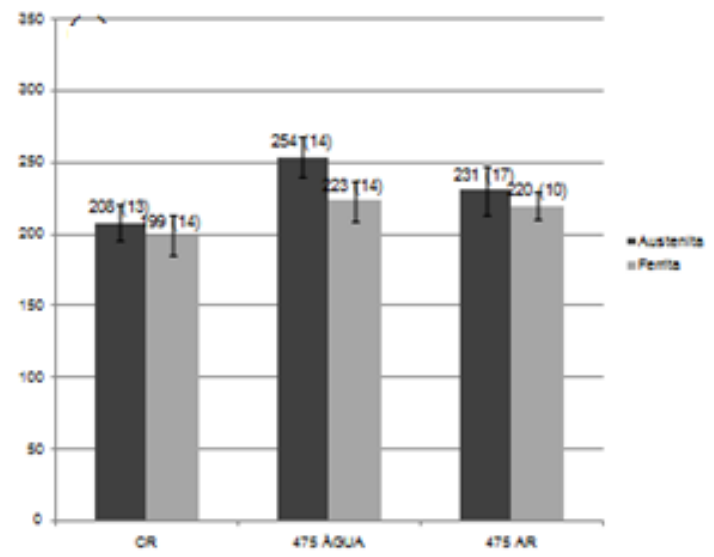

Figura 3: Resultado de microdureza Vickers para as 3 condições das amostras do aço UNS S32304

\subsection{Ensaios DL-EPR}

A Figura 4 ilustra o resultado do ensaio DL-EPR para as 3 amostras. O grau de sensitização das amostras foi obtido a partir da razão entre Ir (pico da corrente catódica) e la (pico da corrente anódica).
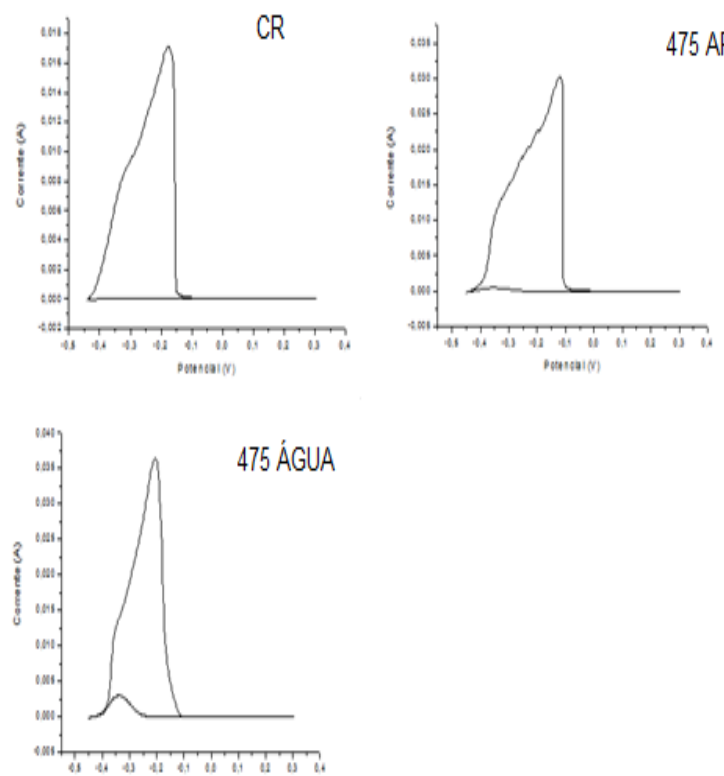

Figura 4: Resultados dos ensaios DL-EPR para as 3 amostras.

A Figura 5 mostra o grau de sensitização calculado. A fase $\alpha$ ' é rica em cromo e sua precipitação acarreta na depleção deste elemento nas regiões adjacentes, o que é prejudicial para a resistência à corrosão, por isso é observada uma maior sensitização nas amostras tratadas [3,6]. A amostra 475 ÁGUA (meio de resfriamento mais severo) apresentou maior microdureza em ambas as fases, o que pode indicar, segundo a literatura, maior precipitação de $\alpha$ ', logo sua resistência à corrosão foi afetada em maior grau [9].

\subsection{Relação entre tensão residual e resistência à corrosão}

A Tabela 2 mostra a macrotensão calculada para as amostras em cada uma das condições, a partir das microtensões residuais.

Tabela 2: Macrotensões calculadas das amostras em MPa.

\begin{tabular}{|c|c|c|c|}
\hline Amostra & CR & 475 AR & 475 ÁGUA \\
\hline $\begin{array}{c}\text { Macrotensão } \\
\text { (MPa) }\end{array}$ & $-265(1)$ & $-184,1(2)$ & $-159(2)$ \\
\hline
\end{tabular}




\section{Grau de sensitização (Ir/la)}

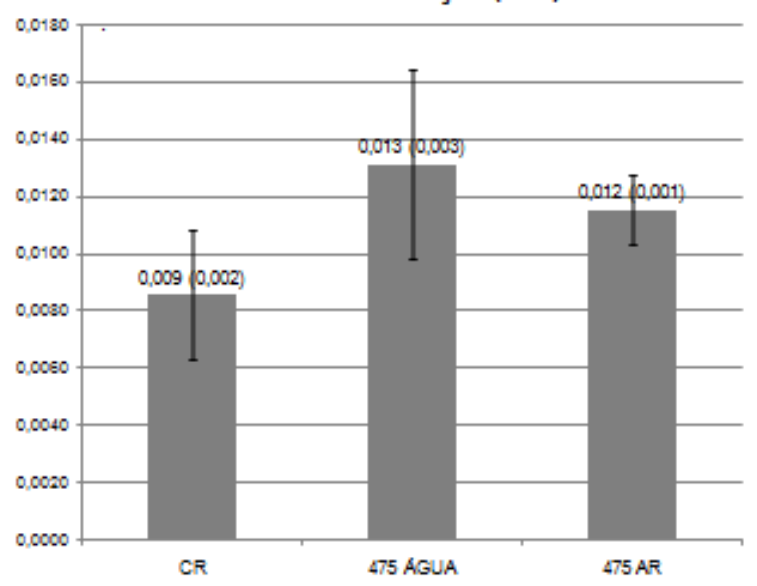

Figura 5: Graus de sensitização obtidos através do ensaio DL-EPR para as 3 amostras.

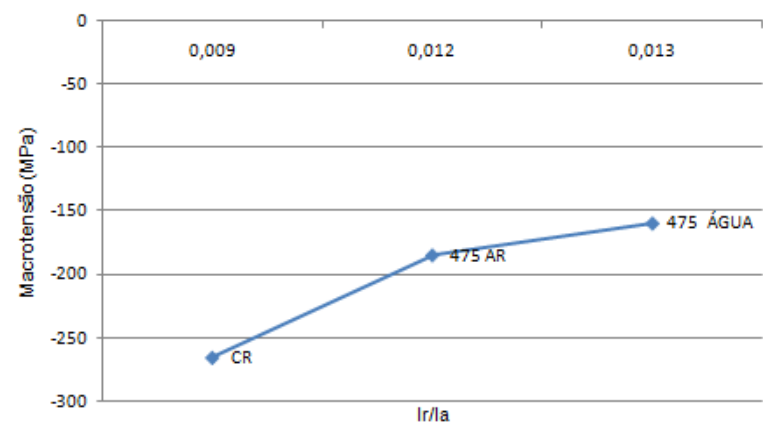

Figura 6: Correlação entre a macrotensão e o grau de sensitização.

Através da Figura 6 concluí-se que o aumento da macrotensão implica em diminuição do grau de sensitização da amostra. Um maior nível de tensões compressivas na liga pode ser benéfico para a estabilidade do filme passivo. A razão entre $\mathrm{Cr} / \mathrm{Fe}$ na camada de óxido tende a aumentar com a elevação das tensões compressivas [10].

\section{Conclusão}

Tratamentos térmicos à temperatura de $475^{\circ} \mathrm{C}$ promovem a precipitação de fases deletérias e alteram o perfil de tensões residuais no aço inoxidável lean duplex. A formação da fase alfa linha pode explicar a elevação de microdureza e diminuição da resistência à corrosão do aço nessa faixa de temperatura. A relação entre a macrotensão e o grau de sensitização indica que tensões residuais compressivas favorecem a estabilidade da camada de óxido, consequentemente, auxilia a resistência à corrosão.

\section{Referências}

[1] Gunn, RN. Duplex stainless steels: microstructure, properties and applications. $3^{a}$ edição. Cambridge: Woodhead Publishing; 2003.

[2] Withers, PJ;Bhadeshia HKDH. Residual stress part 2: nature and origins, Materials science and technology. 2011;17: 366-375.

[3] Lo, K.H.; Shek, C.H.; Lai, J.K.L. Recent developments in stainless steel. Materials Science and Engineering, p. 39-104, 2009.

[4] ASTM E1558. Standard guide for electrolytic polishing of metallographic specimens. ASTM International. 2009.

[5] Dakhlaoui R.; Baczman A.; Brahamski C.; Wronski S.; Wierzbanowski K.; Oliver EC. Effect of residual stresses on individual phase mechanical properties of austeno-ferritic duplex stainless steel. Acta Materialia. 2006; 54: 5027-5039.

[6] ASTM E407-07.Standard Practice for Microetching Metals and Alloys. ASTM International, 2011.

[7] Tavares, S.S.M.; Terra, V.F.; De Lima Neto, P.; Matos, D.E. Corrosion Resistance Evaluation of the UNS S31803 Duplex Stainless Steel Aged at Low Temperatures $\left(350\right.$ to $550^{\circ} \mathrm{C}$ ) Using DLEPR tests. Journal of Materials Science. Vol. 40. 4025-4028, 2005. [8] Chiaverini V. Aços e ferros fundidos. 6ª edição. São Paulo: ABM; 1988.

[9] Van Boven, G.; Chen, W.; Rogge, R. The role of residual stress in neutral $\mathrm{pH}$ stress corrosion cracking of pipeline steels. Part I: Pitting and cracking occurrence. Acta Materialia. 2007, p. 29-42.

[10] Baczmanski, A; et al. Examination of mechanical behavior of aged duplex steel using $X$-ray and neutron diffraction methods. Archives of metallurgy and materials.V.53.2008.

[11] Vignal, V.; Delruea, O.; Heintz O.; Peultier, J. Influence of the passive film properties and residual stresses on the micro-electrochemical behavior of duplex stainless steels. Electrochimica Acta.2010.

\section{Agradecimentos}

Os autores agradecem à FAPES pela bolsa de Mestrado, e aos técnicos e engenheiros responsáveis pelos laboratórios da Universidade Federal do Espírito Santo e Universidade Federal Fluminense utilizados neste trabalho. 
